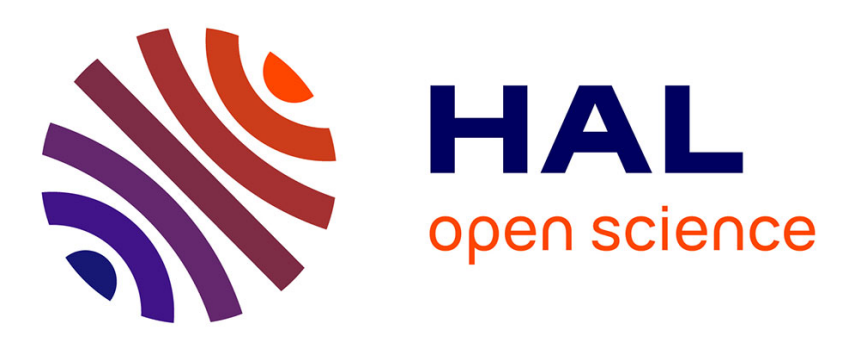

\title{
Electro-Refraction in Standard and Symmetrically Coupled Ge/SiGe Quantum Wells
}

\author{
Jacopo Frigerio, Vladylav Vakarin, Papichaya Chaisakul, Andrea Ballabio, \\ Daniel Chrastina, Marco Leone, Xavier Le Roux, Laurent Vivien, Giovanni \\ Isella, Delphine Marris-Morini
}

\section{To cite this version:}

Jacopo Frigerio, Vladylav Vakarin, Papichaya Chaisakul, Andrea Ballabio, Daniel Chrastina, et al.. Electro-Refraction in Standard and Symmetrically Coupled Ge/SiGe Quantum Wells. Nanoscience and Nanotechnology Letters, 2017, 9 (7), pp.1123 - 1127. 10.1166/nnl.2017.2443 . hal-02883611

\section{HAL Id: hal-02883611 https://hal.science/hal-02883611}

Submitted on 29 Jun 2020

HAL is a multi-disciplinary open access archive for the deposit and dissemination of scientific research documents, whether they are published or not. The documents may come from teaching and research institutions in France or abroad, or from public or private research centers.
L'archive ouverte pluridisciplinaire HAL, est destinée au dépôt et à la diffusion de documents scientifiques de niveau recherche, publiés ou non, émanant des établissements d'enseignement et de recherche français ou étrangers, des laboratoires publics ou privés. 


\title{
Electro-Refraction in Standard and Symmetrically Coupled Ge/SiGe Quantum Wells
}

\author{
Jacopo Frigerio ${ }^{1, *}$, Vladylav Vakarin², Papichaya Chaisakul ${ }^{2}$, Andrea Ballabio ${ }^{1}$, Daniel Chrastina ${ }^{1}$, \\ Marco Leone ${ }^{1}$, Xavier Le Roux², Laurent Vivien², Giovanni Isella ${ }^{1}$, and Delphine Marris-Morini² \\ ${ }^{1}$ L-NESS, Dipartimento di Fisica del Politecnico di Milano, Polo di Como, via Anzani 42, 22100 Como, Italy \\ ${ }^{2}$ Centre de Nanosciences et de Nanotechnologies, Université Paris Sud, CNRS, Université Paris Saclay, 91405 Orsay, France
}

\begin{abstract}
Electro-refraction in standard (sQW) and coupled (cQW) Ge/SiGe quantum wells grown on Si have been investigated by means of optical transmission measurements performed on planar waveguides. The anomalous Quantum confined Stark Effect observed in the coupled quantum well structure strongly enhance the electro-refractive effect with respect to SQW.
\end{abstract}

Keywords: Germanium, Quantum Wells, Silicon Photonics, Modulators.

In the last decade, optical devices based on $\mathrm{Ge} / \mathrm{SiGe}$ quantum wells deposited on Si have undergone an impressive development driven by the envisioned applications in silicon photonics. The strong quantum confined Stark effect (QCSE) observed in this material system, has opened a path toward the realization of compact and efficient optical modulators. Intensity modulation at $1490 \mathrm{~nm}^{2-4}$ and at $1550 \mathrm{~nm}^{5,6}$ has been demonstrated in different exciting works, as well as high-speed operation. ${ }^{2}$ Thanks to their compactness, $\mathrm{Ge} / \mathrm{SiGe} \mathrm{QW}$ modulators can reach power consumption levels as low as $10 \mathrm{fJ} / \mathrm{bit}^{2}$, thus meeting the very aggressive requirements for on-chip optical interconnects. ${ }^{7}$ Composition and thicknesses of $\mathrm{Ge} / \mathrm{SiGe}$ MQW can be finely tailored in order to engineer the material bandgap and to consequently address a very wide range of modulation wavelengths. This approach has been exploited to demonstrate intensity modulation at $1300 \mathrm{~nm}$ by increasing the compressive strain in the Ge layers in $\mathrm{Ge} / \mathrm{Si}_{0.35} \mathrm{Ge}_{0.65}$ grown on a $\mathrm{Si}_{0.3} \mathrm{Ge}_{0.7}$ buffer ${ }^{8-10}$ or simply by reducing the well thickness in $\mathrm{Ge} / \mathrm{Si}_{0.15} \mathrm{Ge}_{0.85} \mathrm{MQW} .{ }^{11}$ All the aforementioned modulators work by exploiting QCSE of the first excitonic transition (cГ1-HH1), nevertheless, also the second excitonic transition (cГ1-LH1) was investigated. ${ }^{12}$ Recently, an integrated optical link made by a Ge/SiGe MQW modulator and photodetector connected through a low-loss $\mathrm{SiGe}$ waveguide was demonstrated. ${ }^{13}$ Remarkably, all the devices were monolithically integrated on silicon by a single epitaxial growth. This work has stimulated the study of SiGe as a new material platform for silicon photonics and several fundamental components

\footnotetext{
*Author to whom correspondence should be addressed.
}

of the passive optical circuitry has been demonstrated. ${ }^{14}$ An excellent review of optical modulators based on Ge/SiGe MQW can be found in Ref. [15]. Ge/SiGe quantum wells have also been successfully employed to realize other silicon compatible integrated optical components such as inter-band ${ }^{16}$ and inter-subband ${ }^{17}$ photodetectors and light emitting diodes. ${ }^{18,19}$ QCSE causes strong variations in the absorption spectrum, leading to a significant change of the effective index as stated by Kramers-Kronig relations, thus the QCSE can be used to realize efficient phase modulators. In this work, we compare the electro-refractive effect in $\mathrm{Ge} / \mathrm{SiGe}$ standard (sQW) and symmetrically coupled (cQW) Ge/SiGe quantum wells deposited on silicon. The heterostructures were grown by Low Energy Plasma enhanced chemical vapor deposition (LEPECVD) $)^{20}$ on $100 \mathrm{~mm} n$-Si(001) substrates with a resistivity of 1-10 $\Omega \mathrm{cm}$. Before the heteroepitaxial growth, the substrates were dipped in an aqueous hydrofluoric acid solution for 30 seconds to remove the native oxide. The first part of the structure consists for both samples of a $\mathrm{Si}_{1-y} \mathrm{Ge}_{y}$ graded buffer, with a total thickness of $13 \mu \mathrm{m}$, where the Ge concentration $y$ was linearly raised from $0 \%$ to $90 \%$ with a grading rate of $7 \% / \mu \mathrm{m}$. The growth rate was $5-10 \mathrm{~nm} / \mathrm{s}$, while the substrate temperature was linearly decreased from $740{ }^{\circ} \mathrm{C}$ to $525^{\circ} \mathrm{C}$. The graded buffer was then capped with a $2 \mu \mathrm{m}$ thick $p$-doped $\left(5 \times 10^{18} \mathrm{~cm}^{-3}\right) \mathrm{Si}_{0.1} \mathrm{Ge}_{0.9}$ layer to form a fully relaxed virtual substrate (VS) and the $p$-type contact of the $p-i-n$ structure embedding the heterostructures. The threading dislocation density was $6 \times 10^{6} \mathrm{~cm}^{2}$ as measured by chemical defect etching. The sQW consists of 


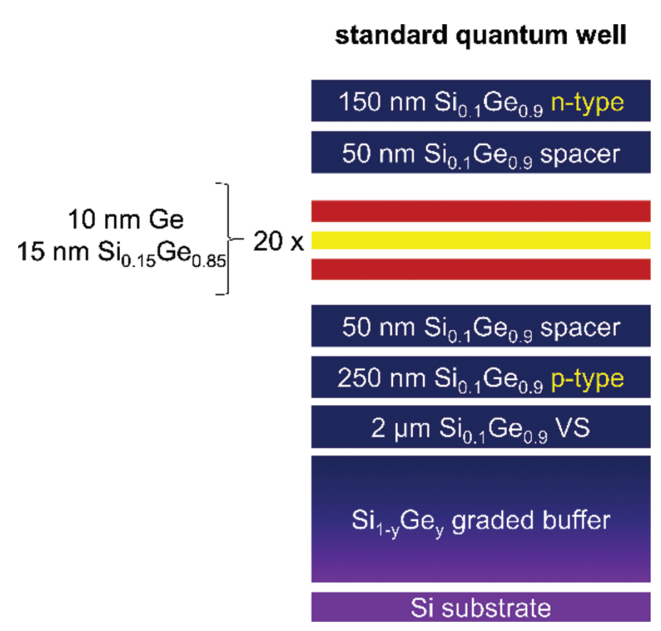

Fig. 1. Schematic of the sample with detailed growth steps.

20 repetitions of the following structure $(10 \mathrm{~nm} \mathrm{Ge}$ well+ $15 \mathrm{~nm} \mathrm{Si}_{0.15} \mathrm{Ge}_{0.85}$ barrier) while the cQW consists of seven repetitions of the following structure $(10 \mathrm{~nm} \mathrm{Ge}$ well + $3 \mathrm{~nm} \mathrm{Si} \mathrm{Si}_{0.15} \mathrm{Ge}_{0.85}$ inner barrier $+10 \mathrm{~nm}$ Ge well $+37 \mathrm{~nm}$ $\mathrm{Si}_{0.15} \mathrm{Ge}_{0.85}$ outer barrier). The thickness of the $\mathrm{QW}$ region is similar for both the samples. The quantum well stacks were grown at $475{ }^{\circ} \mathrm{C}$ at a rate of $1 \mathrm{~nm} / \mathrm{s}$. Individual layer thicknesses and compositions were designed to realize a strain-symmetrized structures. Finally a $200 \mathrm{~nm}$ phosphorous doped $\left(1 \times 10^{19} \mathrm{~cm}^{-3}\right) \mathrm{Si}_{0.1} \mathrm{Ge}_{0.9} n$-type contact layer was deposited for both the samples. A cross section of the structures is shown in Figure 1.

Layer compositions and strain states were measured by high-resolution X-ray diffraction (HR-XRD) by using a PANalytical X'Pert PRO MRD diffractometer. Outof-plane and in-plane lattice parameters, were measured (relative to the Si reflection) for the VS peak and the superlattice satellites. Ge content and strain were then obtained using the known lattice parameters for relaxed $\mathrm{SiGe}$ alloys ${ }^{21}$ and interpolated elastic constants of $\mathrm{Si}$ and Ge. ${ }^{22}$ The final composition of the VS for both the samples was found to be $90.6 \%$ (with a residual in-plane strain of $0.05 \%$ ). The in-plane lattice parameter of the MQW stack is the same as that of the VS for $\mathrm{sQW}$ and cQW, meaning that the heterostructure stacks are coherently matched to the VS. From the reciprocal space maps (see Fig. 2) it can be noticed that the diffraction peaks from the VS and the heterostructures are broadened perpendicular to the relaxation line (the line which joins the Bragg peak to the origin of reciprocal space) due to the mosaicity in the VS. The good crystalline quality of the samples can be inferred by the high number of satellite peaks that are visible in the reciprocal space maps.

In order to investigate the electro-refractive effect in $\mathrm{Ge} / \mathrm{SiGe}$ standard and coupled QWs, $64 \mu \mathrm{m}$ long, $100 \mu \mathrm{m}$ wide planar waveguides have been processed. The waveguides were patterned by optical lithography and then dry coupled quantum well

$150 \mathrm{~nm} \mathrm{Si} \mathrm{i}_{0.1} \mathrm{Ge}_{0.9} \mathrm{n}$-type

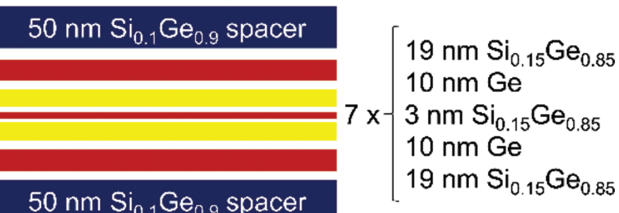

$50 \mathrm{~nm} \mathrm{Si}{ }_{0.1} \mathrm{Ge}_{0.9}$ space

$250 \mathrm{~nm} \mathrm{Si} \mathrm{i}_{0.1} \mathrm{Ge}_{0.9}$ p-type

$2 \mu \mathrm{m} \mathrm{Si} \mathrm{i}_{0.1} \mathrm{Ge}_{0.9} \mathrm{VS}$

$\mathrm{Si}_{1-y} \mathrm{Ge}_{\mathrm{y}}$ graded buffer

Si substrate etched to the $p$-doped $\mathrm{Si}_{0.1} \mathrm{Ge}_{0.9}$ layer. The sidewall roughness of the etched mesa was smoothened by hydrogen peroxide $\left(\mathrm{H}_{2} \mathrm{O}_{2}\right)$ solution. $100 \mathrm{~nm}$ of silicon dioxide were deposited as passivation layer on the left and right walls of the waveguide by plasma-enhanced chemical vapor deposition (PECVD). For $n$ and $p$ contacts $10 \mathrm{~nm}$ of Ti and $300 \mathrm{~nm}$ of Au was evaporated and lifted off. The measurements have been performed at room temperature with a spectral resolution of $0.1 \mathrm{~nm}$. A tunable laser emitting light from 1250 to $1450 \mathrm{~nm}$ with a power of $1 \mathrm{~mW}$ has been used. Light from the laser has been butt coupled into the planar waveguide using a taper-lensed fiber, which has been positioned to inject light in the waveguide region not covered by the top metal contact to reduce optical losses. An objective has been used to couple the output light into a photodetector. The etched facets of the waveguides are partially reflective, thus a Fabry-Perot (FP) cavity is formed within the waveguide. As a consequence, the absorption spectra of the heterostructures are modulated by FP fringes. The effective index variation can be deduced by measuring the spectral shift of the FP fringes as a function of the electric field applied to the heterostructures. The detailed procedure can be found in Refs. [23, 24].

The effective index variation as a function of different applied electric fields for $\mathrm{sQW}$ and $\mathrm{cQW}$ is reported in Figures 3(a) and (b) respectively.

For standard quantum wells, the effective index variation increases with the applied electric field and decreases as we move away from the main excitonic transition. Such a behaviour is perfectly consistent with QCSE. An effective index variation up to $1.3 \times 10^{-3}$ is measured at $1475 \mathrm{~nm}$ (see Fig. 3(a)) with an applied electric field of $88 \mathrm{kV} / \mathrm{cm}$, which corresponds to an applied bias voltage of $8 \mathrm{~V}$, with an associated $V_{\pi} L_{\pi}$ figure of merit of $0.46 \mathrm{~V} \mathrm{~cm}$. This value is comparable to those reported for III-V standard quantum wells ${ }^{25,26}$ and competitive with those of silicon. ${ }^{27}$ In the case of cQW the effective index variation has a local maximum for all the considered wavelengths 

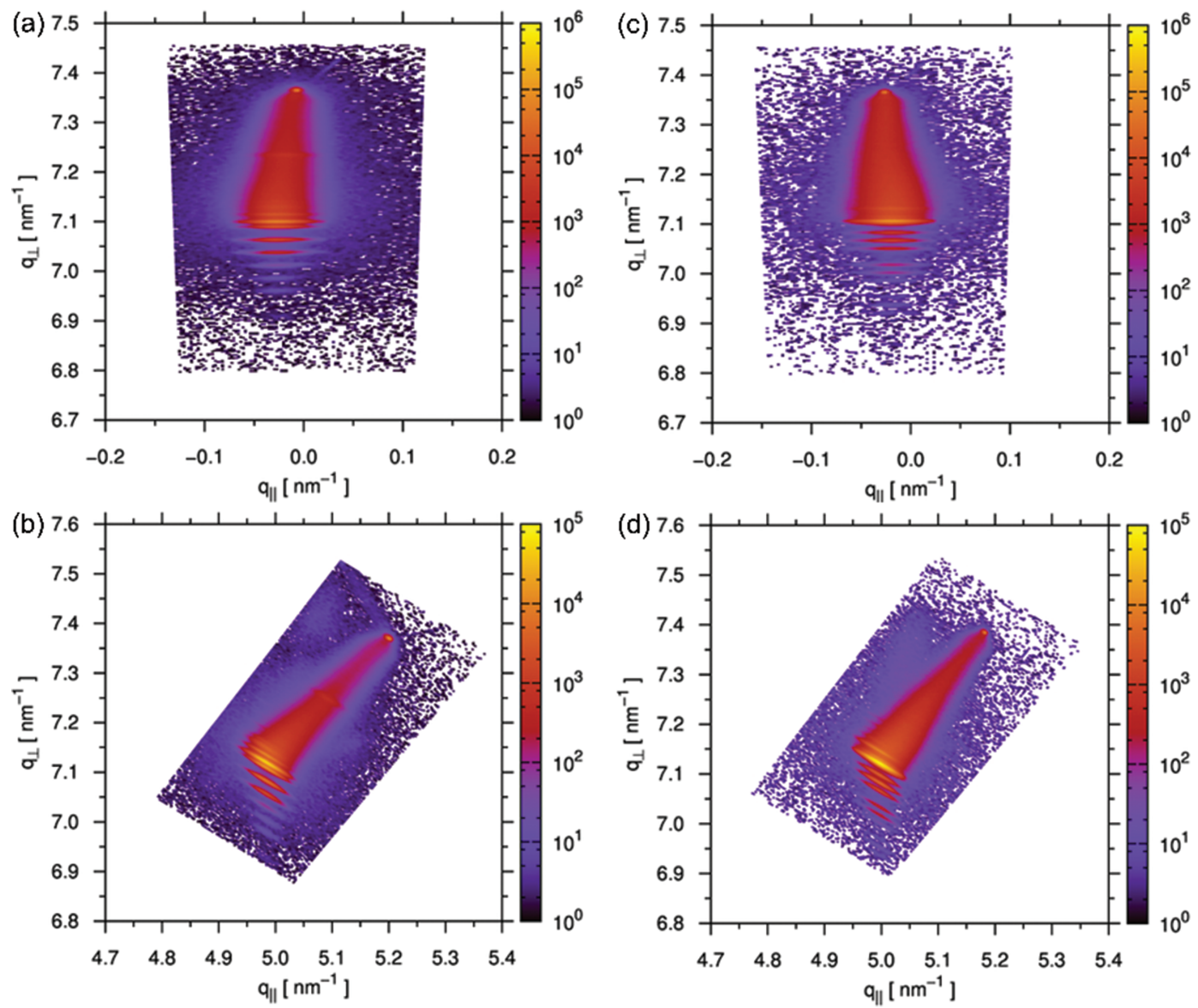

Fig. 2. Reciprocal space maps of the $\mathrm{SQW}$ ( $\mathrm{a}$ and b) and of the $\mathrm{cQW}(\mathrm{c}$ and d) with respect to the $224 \mathrm{Si}$ reflection and to the $004 \mathrm{Si}$ reflection.

at $30 \mathrm{kV} / \mathrm{cm}$ and it is not monotonically decreasing at increasing wavelength. An effective index variation of $2.3 \times 10^{-3}$ is obtained for $30 \mathrm{kV} / \mathrm{cm}(1.5 \mathrm{~V})$ at $1421 \mathrm{~nm}$ (see Fig. 3(b)), with an associated $V_{\pi} L_{\pi}$ figure of merit of $0.045 \mathrm{Vcm}$. This value is one order of magnitude higher with respect to $\mathrm{sQW}$. In the case of $\mathrm{sQW}$, the absorption spectra at different applied electric fields show a clear
QCSE (see Fig. 4(a)). By increasing the electric field, the excitonic peak shifts towards longer wavelengths and the intensity is progressively reduced. In the case of $\mathrm{cQW}$, we can observe two peaks, which are very close in energy. By increasing the electric field, the intensity of the absorption peak at longer wavelength progressively increases, while the intensity of the other peak is decreasing (see Fig. 4(b)).
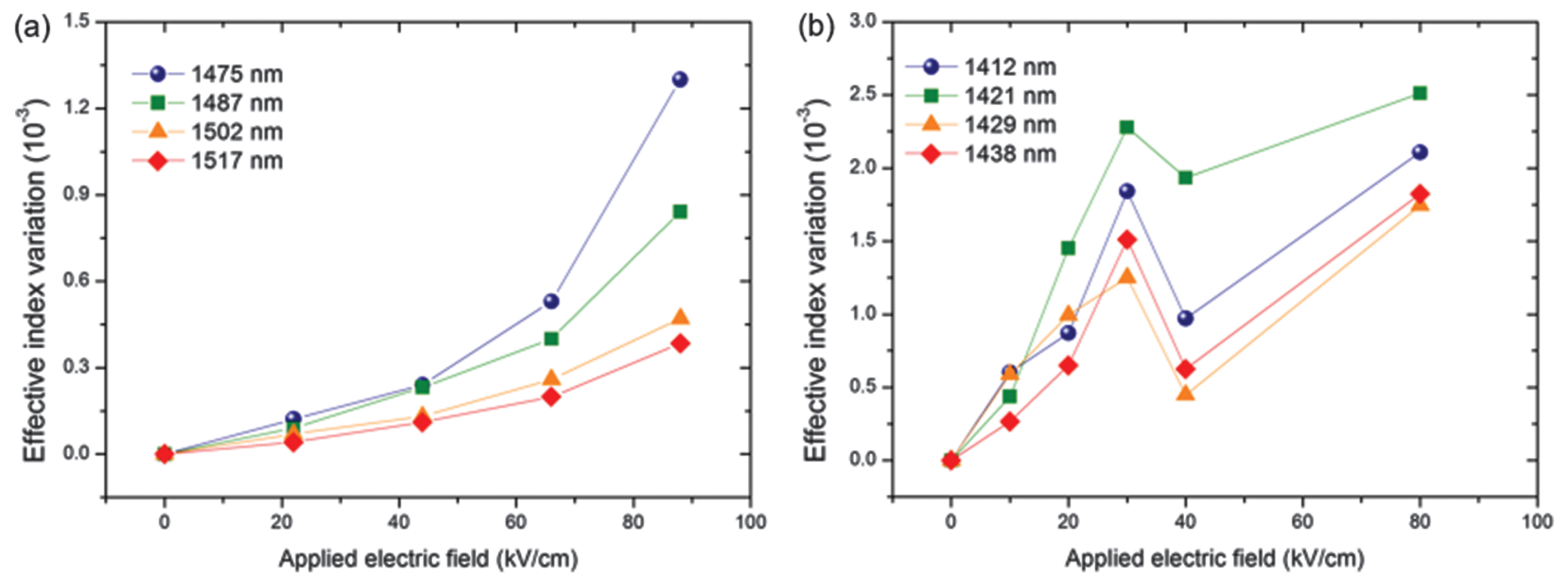

Fig. 3. Effective index variation as a function of the applied electric field at different wavelengths for sQW (a) and cQW (b). 

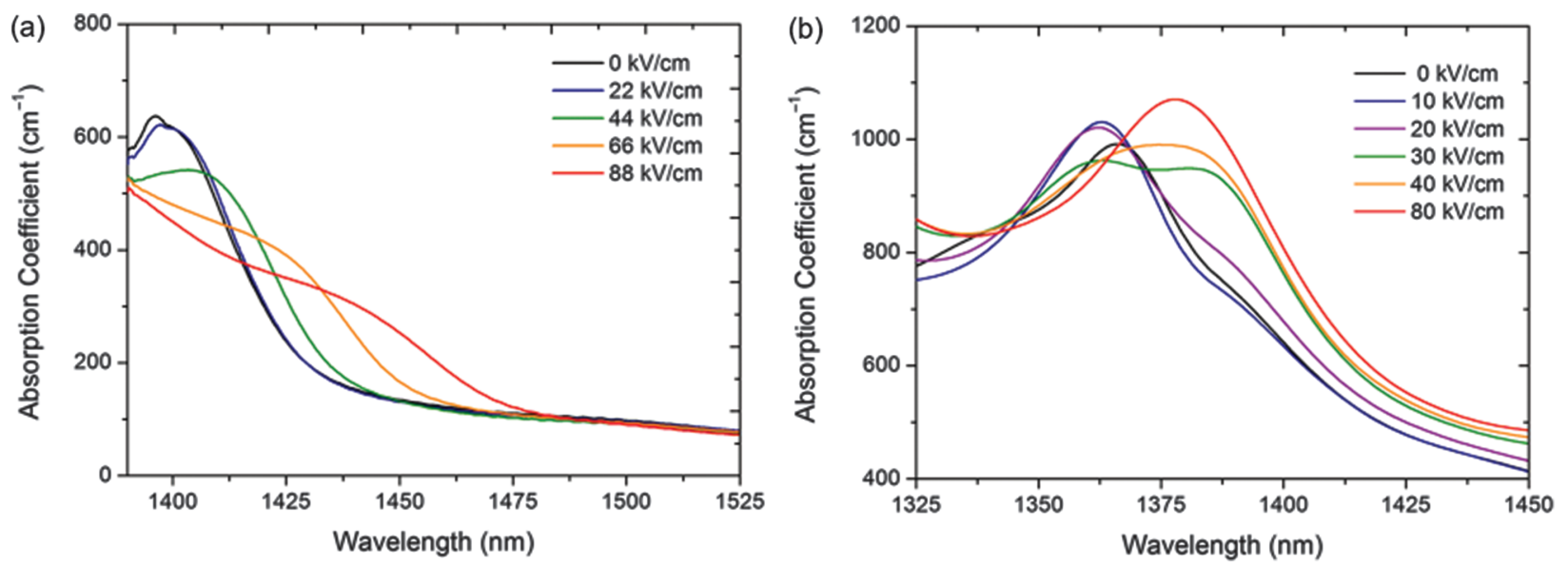

Fig. 4. Smoothed absorption spectra for different applied electric fields for sQW (a) and cQW (b).

The enhanced electro-refractive effect observed in the $\mathrm{cQW}$ structure arises from two main spectral features. First of all there is a huge absorption variation at an intermediate electric field ( $30 \mathrm{kV} / \mathrm{cm}$ for this structure) which causes the presence of a local maximum in the effective index variation as a function of the electric field. On the contrary, for the sQW there is only a monotonic increase of the effective index with increasing electric field. Moreover, the two main absorption peaks in the cQW do not shift in energy as the electric field increases, allowing the exploitation of the electro-refractive effect closer to the excitonic resonances without high losses. This is not possible in sQW because the excitonic peak shift toward longer wavelengths as the electric field increases. A detailed explanation of the QCSE in cQW can be found in Ref. [28].

To summarize, we have investigated the electrorefraction in $\mathrm{Ge} / \mathrm{SiGe}$ standard and symmetrically coupled quantum wells. The cQW shows an enhanced electrorefractive effect with an effective index variation higher than $2 \times 10^{-3}$ under a moderate electric field. In order to exploit the potentiality of $\mathrm{Ge} / \mathrm{SiGe} \mathrm{CQW}$ as compact, high speed and low power consumption optical modulators, the active region will have to be integrated into an interferometric structure such as a Mach-Zehnder interferometer. The integration of $\mathrm{QW}$ active regions with low-loss $\mathrm{SiGe}$ waveguides on top of graded buffer is a promising approach, as sharp bends and Mach-Zehnder interferometers ${ }^{14}$ as well as the integration of a passive SiGe waveguide with an electro-absorption modulator and a photodetector ${ }^{13}$ were demonstrated recently.

Acknowledgment: The fabrication of the device was performed at the nano-center CTU-IEF-Minerve, which is partially funded by the 'Conseil General de l'Essonne.' This work was partly supported by the French RENATECH network. Delphine Marris-Morini acknowledges support by the Institut Universitaire de France. Marie Curie
International Outgoing Fellowships through grant agreement PIOF-GA-2013-629292 MIDEX is partly acknowledged. This project has received funding from the European Research Council (ERC) under the European Union's Horizon 2020 research and innovation programme (grant agreement $\mathrm{N}^{\circ}$ 639107-INsPIRE).

\section{References and Notes}

1. Y. H. Kuo, Y. Lee, Y. Ge, S. Ren, J. E. Roth, T. I. Kaminis, D. A. B. Miller, and J. S. Harris, Nature 437, 1334 (2005).

2. P. Chaisakul, D. Marris-Morini, M. S. Roufied, G. Isella, D. Chrastina, J. Frigerio, X. Le Roux, S. Edmond, J. R. Coudevylle, and L. Vivien, Opt. Express 20, 3219 (2012).

3. S. Ren, Y. Rong, T. I. Kaminis, J. S. Harris, and D. A. B. Miller, Appl. Phys. Lett. 98, 151108 (2011).

4. S. Ren, Y. Rong, S. A. Claussen, R. K. Schaevitz, T. I. Kaminis, J. S. Harris, and D. A. B. Miller, IEEE Photon. Tech. Lett. 24, 461 (2012).

5. Y. H. Kuo, Y. K. Lee, Y. Ge, S. Ren, J. E. Roth, T. I. Kamins, D. A. B. Miller, and J. S. Harris, IEEE J. Sel. Top. Quantum Electron. 12, 1503 (2006).

6. D. C. S. Dumas, K. Gallacher, S. Rhead, M. Myronov, D. R. Leadley, and D. J. Paul, Optics Express 22, 19284 (2014).

7. D. A. B. Miller, Opt. Express 20, A293 (2012).

8. L. Lever, Y. Hu, M. Myronov, X. Liu, N. Owens, F. Y. Gardes, I. P. Marko, S. J. Sweeney, Z. Ikonić, D. R. Leadley, G. T. Reed, and R. W. Kelsall, Opt. Lett. 36, 4158 (2011).

9. M. S. Rouifed, P. Chaisakul, D. Marris-Morini, J. Frigerio, G. Isella, D. Chrastina, S. Edmond, X. Le Roux, J. R. Coudevylle, and L. Vivien, Opt. Lett. 37, 3960 (2012).

10. M. S Rouifed, D. Marris-Morini, P. Chaisakul, J. Frigerio, G. Isella, D. Chrastina, S. Edmond, X. Le Roux, J. R. Coudevylle, D. Bouville, and L. Vivien, IEEE J. Sel. Top. Quantum Elect. 20, 33 (2014).

11. P. Chaisakul, J. Frigerio, D. Marris-Morini, V. Vakarin, D. Chrastina, G. Isella, and L. Vivien, J. Appl. Phys. 116, 193103 (2014).

12. P. Chaisakul, D. Marris-Morini, M. S. Rouifed, J. Frigerio, G. Isella, D. Chrastina, J. R. Coudevylle, X. Le Roux, S. Edmond, D. Bouville, and L. Vivien, Appl. Phys. Lett. 102, 191107 (2013).

13. P. Chaisakul, D. Marris-Morini, J. Frigerio, D. Chrastina, M. S. Rouifed, S. Cecchi, P. Crozat, G. Isella, and L. Vivien, Nat. Photon. 8, 482 (2014).

14. V. Vakarin, P. Chaisakul, J. Frigerio, A. Ballabio, X. Le Roux, J. R. Coudevylle, D. Bouville, D. Perez-Galacho, L. Vivien, G. Isella, and D. Marris-Morini, Opt. Express 23, 30821 (2015). 
15. P. Chaisakul, D. Marris-Morini, M. S. Rouifed, J. Frigerio, D. Chrastina, J. R. Coudevylle, X. Le Roux, S. Edmond, G. Isella, and L. Vivien, Sci. Tech. Adv. Mat. 15, 014601 (2014).

16. P. Chaisakul, D. Marris-Morini, G. Isella, D. Chrastina, M. S. Rouifed, X. Le Roux, S. Edmond, E. Cassan, J. R. Coudevylle, and L. Vivien, IEEE Phot. Tech. Lett. 23, 1430 (2011).

17. K. Gallacher, A. Ballabio, R. W. Millar, J. Frigerio, A. Bashir, I. MacLaren, G. Isella, M. Ortolani, and D. J. Paul, Appl. Phys. Lett. 108, 091114 (2016).

18. K. Gallacher, P. Velha, D. J. Paul, S. Cecchi, J. Frigerio, D. Chrastina, and G. Isella, Appl. Phys Lett. 101, 211101 (2012).

19. P. Chaisakul, D. Marris-Morini, G. Isella, D. Chrastina, N. Izard, X. Le Roux, S. Edmond, J. R. Coudevylle, and L. Vivien, Appl. Phys. Lett 99, 141106 (2011).

20. G. Isella, D. Chrastina, B. Rössner, T. Hackbarth, H. J. Herzog, U. König, and H. von Känel, Solid State Electron. 48, 1317 (2004).
21. J. P. Dismukes, L. Ekstrom, and R. J. Paff, J. Phys. Chem. 68, 3021 (1964).

22. J. J. Wortman and R. A. Evans, J. Appl. Phys. 36, 153 (1965).

23. J. Frigerio, P. Chaisakul, D. Marris-Morini, S. Cecchi, M. S. Roufied, D. Chrastina, G. Isella, and L. Vivien, Appl. Phys. Lett. 102, 061102 (2013).

24. J. Frigerio, P. Chaisakul, D. Marris-Morini, S. Cecchi, M. S. Roufied, G. Isella, and L. Vivien, Proc. SPIE 8767, Integrated Photonics: Materials, Devices, and Applications II 87670B (2013).

25. J. S. Wiener, D. A. B. Miller, and D. S. Chemla, Appl. Phys. Lett. 50, 842 (1987).

26. L. Glick, F. K. Reinhart, G. Weimann, and W. Schlapp, Appl. Phys. Lett. 48, 989 (1986).

27. M. J. W. Green, M. J. Rooks, L. Sekaric, and Y. A. Vlasov, Opt. Express 15, 17106 (2007)

28. J. Frigerio, V. Vakarin, P. Chaisakul, M. Ferretto, D. Chrastina, X. Le Roux, L. Vivien, G. Isella, and D. Marris-Morini, Scientific Reports 5, 15398 (2015).

Received: 1 December 2016. Accepted: 24 March 2017. 